\title{
Status Analysis on the Education Space and Ceremony in Chinese Schools
}

\author{
Yajuan Wang \\ Huanghe Science and Technology College \\ Zhengzhou, China, 450006
}

\begin{abstract}
Education space is a broad space and virtual concept relatively, covering all the elements of the occurrence and development in the educational activities, however, education ceremony, as one of the important elements of education space, relies on the education space and also improves its connotation. Based on the analysis of the definition and the relationship between education space and ceremony, this thesis discusses the current development status of education space and ceremony of the school in China and puts forward some suggestions to promote their coordination and common development
\end{abstract}

Keywords-education space; education ceremony; status and problems

\section{THE RELATIONSHIP BETWEEN EDUCATION SPACE AND CEREMONY}

\section{A. The Formation of Education Space}

"Space" is a creation which consists of some elements of nature, life and society, and these elements can influence each other. As a part of human life and practice, education owns its independent structure and functional system, which be within the nature and social system. Hence unified the "space" and "education", the concept of "education space" is formed. Education space is a combination which formed by itself occurrence space and social space. The education space owns the independence, which means that the education and teaching activities can complete in the exclusive space like campus; at the same time it also owns the openness that is affected by the overall social environment and elements. Therefore the education space can complete its own transformation and renewal through the circulation between the inner space and out space. The development of education space has changed from the original natural education space to the social education space school after the appearance of school and the modern information technology education space, which also accompanied by the changes and development of education form and education philosophy. The evolution of education space is the process from natural education to institutionalized education and formal education actually. In this process, different education stages of development correspond to different education system and education form.

\section{B. From Education Space to Education Ceremony}

Modern education space refers to a place that is a combination of the knowledge place which composed of all kinds of science and skills and thought space which composed of moral quality, where can carry out educational activities. The connotation of modern education space that derives from the school space and education environment, but higher than the sum of them is a relative ideal and board conceptual model. Education space has contained not only the substantial elements such as schools, subjects, teachers and facilities, but also the virtual elements such as education philosophy, education methods, education activities and educational goals. In addition, the education space also includes the imagination and goal elements which can selfconstruct; self- plan and self- develop. In this space, builders can imagine the questions such as what kind of element are necessary, what kind of elements must or already have and what kind of element need to add, which can make the education more perfect and valuable. Through the interpretation of the connotation of modern education space, space builders can find and think the direction of education development clearly and the differences between the goals and the development of current education system. Specifically, the current education space possesses the elements such as knowledge dissemination, skills teaching and scientific innovation, but ignores the basic elements such as emotional communication, personality building, spiritual care and morality. This kind of education space presents an abnormal status which stresses the knowledge but weaken the psychology, which must be complemented and perfected in the practice of the future. Based on this, the education ceremony should be added into the education space to form a full-scale development ideal education space model.

\section{The Connotation and Function of Education Ceremony}

"Ceremony" is developed accompanying by the development of human society, which is the most ancient concept and elements of the human society and culture. At present, the specific meaning of ceremony in the academe has different interpretations based on their own cultural differences and stage of development. Combined with China's social and cultural traditions and features at this stage, "ceremony" should be understood as a kind of specific behavior undertakes some cultural and social significance under culture continuity and norms. It contains immediacy, 
normalization, influence and coherency features and functions, which is the construction and inheritance of human moral and social order. Correspondingly, "education ceremony" refers to the specific and normalized cultures and social behaviors which are related to the education. The Chinese education ceremony has a long history and a wide variety. From the "Shicaili" (refers to a ceremony that students sacrifice some kinds of vegetables to the wise men) of Western Zhou Dynasty to the "Shuxiuli" (refers to a ceremony that students offer some gifts to their teacher when entering the school) of the Tang Dynasty, to the modern flagraising ceremony, graduation ceremony, anniversary ceremony and the Ceremony of Confucius, adult ceremony, etc., which can be seen as the specific practice of education ceremony.

\section{Unity of Education Space and Ceremony}

As already noted education space includes knowledge space and mind space and education ceremony is the important part and supplementary elements of mind space, at the same time, education ceremony should be practiced in limited mind space, so there exists an inner unified relationship between education space and ceremony. As to say, education space is the development space of education ceremony and education ceremony is the inner ceremony of education space they have the inner unified relationship. As to outward appearance, they supplement each other, they are not only the unified and complementary of cultural inheritance but also of the value of education, they are coordinating and unifying and can't be separated.

\section{ANALYSIS OF PROBlEMS AND CURRENT SitUATION OF EDUCATION CEREMONY IN EDUCATION SPACE OF CHINESE SCHOOLS}

\section{A. The Current Situation of Education Ceremony in Education Space of Chinese Schools}

Judging from the reality, there are many kinds of education ceremony in education space of Chinese school, some inherit traditional culture elements like honors day graduation ceremony rite of passage respect ceremony memorial service and so on as while some ceremony of modern society like CCP admission ceremony league for ceremony flag- raising ceremony and others, each ceremony has its own characteristics. These education ceremony have different continuity effect on each education space, the administrator of school and organizer of ceremony can always seize the chance to take full use of the symbolic meaning of ceremony to combine the form and its connotation, maximum the function of education ceremony to get self-identity realize the goal of ideological and moral education and supplement shortage factor for education space. Now education ceremony in Chinese education space mainly play a positive role on the following level: first, intensify daily education effect and education objectives by education ceremony then take full use of resources effectiveness in education space to improve influence, third motivate initiative of ideological and moral level to improve quality of the whole education.

\section{B. The Problems of Education Ceremony in Education Space of Chinese Schools}

As already noted, there is a screwy development of education space in china, for specific performance is that emphasize scientific knowledge more but ignore ideological and moral education. The education space under the development of modern economy political information science and technology will show the knowledge and skill which adapt to the society more and the practical significance and shortcut approach of these skills but did not supplement necessary moral element. The education ceremony in this education space will show its loneliness but can't give play to the cultural function of education ceremony like resonance shock cohesion and guide.

1) The losing of education ceremony. Education ceremony is the interpretive act of language symbols, it carries some cultural connotation, so we must put into effect with education space in education ceremony that means we should build a education space which can take full use of function and meaning of ceremony so it can be accepted and self-identity more by participator then it can show its effect. But now most education ceremony in china has its drawback, in many participators' eyes. Ceremony is just a ceremony; so many people just regard this meaningful human activity as mechanism and simple formalism and even distort and misunderstand.

2) Void content of education ceremony. Education ceremony must be annotated by specific behavior in education space, the specific behavior includes a whole set of normalize and reutilized process, by using this to show the seriousness and preciseness of education space and increase the infectivity.

Afterwards, the image of modern education ceremony is that inter emptiness simple form and boring process. Like flag-raising ceremony, it assume a lofty connotation that loves the motherland and being bold in contribution, its standardized flow should like this : all people wear the same uniform, playing the national anthem, raise the national flag, all looks solemnly, salute with eyes and singing the national anthem. But nowadays flag-raising ceremony in school pay more attention to shape, participator wear different clothes ,looks loose, whisper to each other, just regard flagraising ceremony as shape, take it in stride don't know the connotation of flag-raising ceremony at all .

3) The distortion of education space. Education ceremony not only has a deep cultural connotation but also have a whole set of normalize and reutilized process in education space, it is a whole process made up of wellconstructed detail and special form.

It can place participator into particular education space via this process, make people fell sympathetic visage. And then deepen the symbolic meaning of ceremony to transmit the implicit meaning better .But now many education ceremonies omit and even distortion structure of education space, make rigorous and normative education ceremony as a not essential interlude. 


\section{BUILD COMPLETE EDUCATION SPACE AND INTENSIFY THE EFFECT OF EDUCATION CEREMONY}

\section{A. Strengthen the Correct Cognition for Education Space and Ceremony}

Sergiovanni, the famous American contemporary education management scientist, once said that school is not only a place can we acquire knowledge but also a education aggregation we pursue and share value and moral development, it has profound humanistic significance and education significance. Based on this viewpoint, school education space should mould and promote participator's ideology morality and faith by using education ceremony. And the correct cognition for education space and ceremony is the precondition for organizer to structure education space and intensify effect of education ceremony.

If organizer knows well about education space and the implication of education ceremony then can he combine education space and ceremony perfectly in concrete practice, release and sublimate all the effect of education ceremony in the suitable value space from one's own ability and belief. Many deficiency of ceremony in education space is just because administrator and organizer don't know or can't know well about its specific characteristics and connotation. Just like begin or finish class ceremony it includes traditional respect for teachers, but now student's even teachers cancel it because they think it is not necessary.

\section{B. Seize the Major Characteristic and Strengthen Structure of Key Element}

Education space is a broader conception while education ceremony also has a multitude of names, so its principle should grasp its major characteristic and key element on concrete practice, it covers three parts.

1) Highlight Status. The development and prevalence of one ceremony always depends on how much people know about it, if people know more people will pay more attention on it, then development degree will be higher and spreading range will be wider, the education ceremony on the basis will be more efficiency. So we should structure and prominent core value of ceremony by surrounding the characteristic of education space.

Education ceremony in education space means annotation of education living also means surmounting of education living, therefore we should distinguish education ceremony with normal education activity, prominent ceremony on scheme and implement, thus form characteristic humanities imprint in education space and make students and teachers accept the importance of education ceremony and then fulfill education ceremony culture consciously.

2) Repetition of Intensification. One of the features of education ceremony is it is repeatable in particular space, not only it has normative system to make itself repeatable but also it need repeat to strengthening memory and deepen influence. Generally speaking, the more ceremony repeats the more people accept it, and the psychological suggestion that ceremony is important will strengthen.

Many ceremonies should be held timed and repeated at a short time in education space like flag-raising ceremony and so on; organizational managers can't make short shrift of it at this time, just weaken for one time will make participator feel this ceremony is dispensable then affect the status of ceremony and its expression in education space.

3) Normalize Process. Normative means solemnity and holy of ceremony, will give people a psychological locating that it cannot be ignored, cannot be changed and cannot be polluted. Durkheim, French sociologist, once said that if one ceremony doesn't have holiness, then it lost it significance. This sentence explains the importance of normative for ceremony in education space.

Ceremony is a cultural activity that people designed carefully, and standards is one of the biggest difference between ceremony and other common public activity, it is precisely because of the criterion on every detail and each program makes the participator are filled with deep esteem and make ceremony be respected.

Education ceremony and space originate from inherent educational concept, and were given new connotation at the new situation. First, the range of thinking and study for education space should not be limited to education ceremony but should consider and structure on all the inner and

exclusive elements about education, it should give people enough space to select and imagine as well as supplement new content with the practice and development of education.

Next, we should digging into the depth of ideological and moral connotations on education ceremony combine traditional value theory with modern, import self-sublation mechanism not only bring new education ceremony in modern value theory but also should make traditional ceremony carrying more massive cultural value.

In the end, we should use dialectical thinking to complete this harmony and unity theoretical model in the fusion interactive of education space and ceremony, and then consummate its connotation. In practice, expand its function, benign interaction with education practice, supplement each other.

\section{REFERENCES}

[1] LiuYannan, The Evolution of Education Space, Henan University, 2009

[2] Wang Jin, The Social Analysis of Education Ceremony, [J] Educational Theory and Practice, 2010 